\title{
COMUNICAÇÃO
}

\section{RESISTANCE OF UNFED FIRST INSTAR DIPETALOGASTER MAXIMUS TO DIFFERENT ENVIROMENTAL CONDITIONS}

\section{Marco Tulio Garcia-Zapata, Manoel Vidal and Philip Davis Marsden}

We have already determined the favourable temperature and humidity conditions for rearing Dipetalogaster maximus ${ }^{1}$. In each of the two experiments described here two newly hatched lots of 40 first instar bugs were studied. One group was maintained in our insectary at a mean temperature of $28^{\circ} \mathrm{C}$ (range $27-30$ ) and a mean humidity of $50 \%$ (range 47-50\%). The second group was maintained in the laboratory during the period October to March when conditions were colder $\left(22^{\circ} \mathrm{C}\right.$, range $10-$ 34 ) and drier (40\% range 10-90). Time to death of these unfed bugs was recorded for all experimental insects.

The results are expressed in Figure 1. They show that first instar bugs kept in drier, colder conditions live significantly longer (mean 145 days, range 94-178) than those kept under our insectary conditions (mean 89 days, range 69-103) $\left(x^{2}=0.582\right.$, $p=0.4555$ ). While our insectary is favourable for rapid rearing of fed bugs $^{1}$, it shortens the life of unfed first instars. These data are compatible with field observations ${ }^{2}$. First instars survived in the cold nocturnal conditions of the Baja California Peninsula to run over sunlit stony ground from 9 a.m. in search of the rare blood meal. Their resistance to starvation is a biological adaptation to an inhospitable ecology.
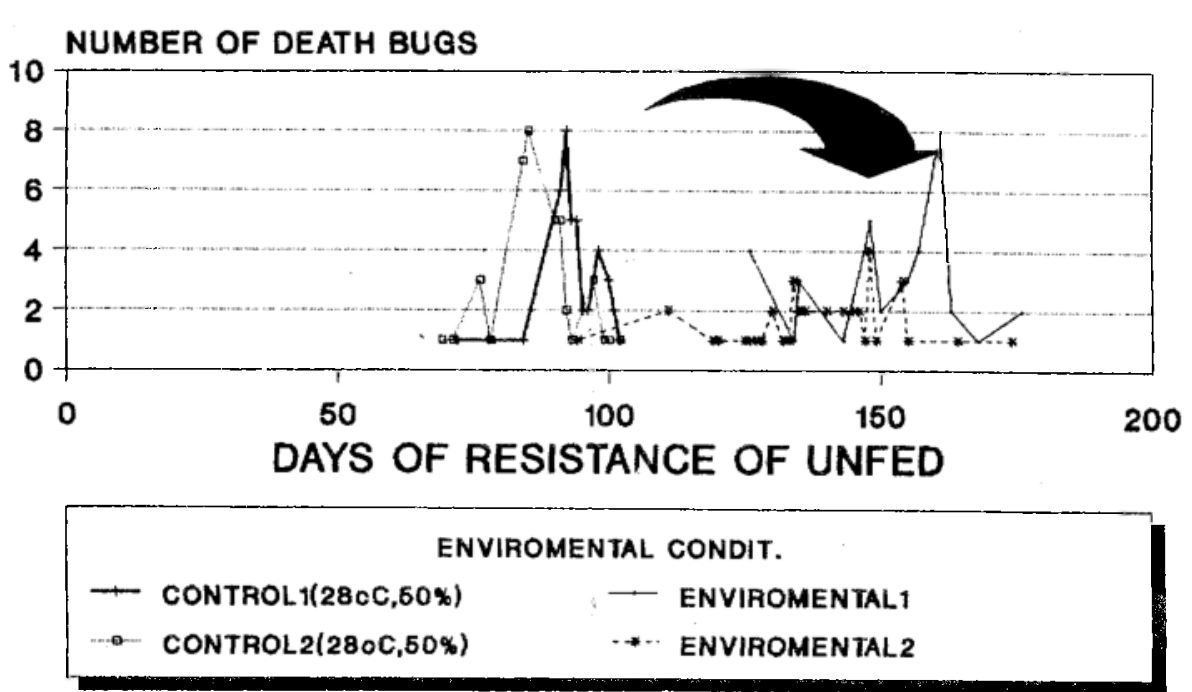

Figure 1-Resistance of unfed first instar Dipetalogaster maximus to different enviromental conditions. Triatomines laboratory, NMT/UnB.

\section{REFERENCES}

1. Barreto AC, Prata AR, Marsden PD, Cuba CC Trigueiro CP. Aspectos biológicos e criação em massa de Dipetalogaster maximus (TJlher, 1894) (Triatominae). Revista do Instituto de Medicina Tropical de São Paulo 23:18-27, 1981.
2. Marsden PD, Cuba CC, Alvarenga NJ, Barreto AC. Report on a field collection of Dipetalogaster maximus. Revista do Instituto de Medicina Tropical de São Paulo 21:202-206, 1979. 